panic attacks often complain of bodily rather than psychological symptoms. This may lead either to failure of recognition or inappropriate referral.

The treatment of panic disorders is varied. Most of the evidence comes from studies which included agoraphobic patients with panic attacks, and concurrent behavioural treatments were usually given. Tricyclic antidepressants, such as imipramine and clomipramine, have an established place in the prevention of panic attacks. Where panic occurs without significant depression some workers have evidence to support the use of low doses of antidepressant drugs, but others have suggested the use of high doses. There is also disagreement about the time of onset of the therapeutic effect, some workers reporting prompt onset, others noting substantial delays. Some panic patients appear very sensitive to unwanted effects of these drugs. Reponse at low doses may suggest a mechanism of action distinct from the antidepressant action seen at higher doses. Although improvement may be maintained for some time after stopping the drugs, over the longer term the outcome is more uncertain. A few benzodiazepines used in doses above the usual anxiolytic ones (e.g. alprazolam, clonazepam, diazepam) have been shown to prevent panic attacks; the evidence for this is most clear for alprazolam, and further studies are in progress. Such response to benzodiazepines is, however, less convincing than that to the tricyclic antidepressants, and there is a danger of dependence. Alternative drugs include the MAOIs and $\beta$ adrenoceptor blockers; the latter are of limited usefulness. All of these treatments can be used in conjunction with behavioural and cognitive therapies. Indeed, preliminary evidence suggests the efficacy of cognitive therapy alone in patients with panics. High consultation rates and limited time in general practice emphasise the need for simple, pragmatic therapies.

Panic attacks can be regarded as a cluster of symptoms which can occur alone or as part of another disorder which has its own place in the classificatory scheme. Controversy attends the nosological status of disorders in which the symptoms of panic occur in conjunction with other disorders (agoraphobia, generalised anxiety, or depression). In the American classification (Revised DSM-III) panic attacks are given primacy and are thought to delineate a separate diagnostic entity (called Panic Disorder). The proposed revision of the ICD uses the term 'Panic Disorder (episodic anxiety)' to describe a disorder in which panic attacks occur as the major feature in the absence of significant anxiety between attacks and a depressive disorder. The meeting preferred the latter convention, as it is unclear whether panic attacks which occur in association with significant generalised anxiety are best considered as a separate disorder or as a more severe form of generalised anxiety disorder.

The meeting also recognised that for research purposes the individual symptom clusters should be considered independently, and it urged longitudinal studies to clarify their natural history and outcome.

The consensus of the meeting was that it is useful descriptively to recognise the symptom cluster of panic attacks which can be defined operationally in terms of features and content. Frequency is a useful, albeit arbitrary, indicator of severity. It was recognised that patients are encountered in whom panic attacks occur in the absence of other significant symptoms. The status of panic disorder as a separate entity was not strongly supported by available clinical and scientific evidence. Finally, although some evidence suggested that panic attacks often represented a severe form of more generalised anxiety, it was premature to attempt to describe the relationships between the various symptom clusters.

Participants: G. W. AshCroft (Aberdeen); G. BEAUMONT (Stockport); J. BONN (London); S. BrandoN (Leicester); A. BRIGGS (Leicester); D. Clark (Oxford); K. Davison (Newcastle-uponTyne); M. G. Gelder (Oxford); D. GoldBerg (Manchester); R. HeRRINGTON (Glasgow); M. C. KHAN (Hartlepool); M. LADER, Chairman (London); M. S. LiPSEDGE (London); A. MACDONALD (London); P. MAguIRE (Manchester); P. T. S. MILLN (Southampton); R. M. MURRAY (London); R. F. Stirton (Leicester); A. C. P. Sims (Leeds); R. P. SNaIth (Leeds); D. Wheatley (Hinchley Wood).

(See also pp 563-564)

\section{Senile Dementia and Parietal Lobe Dysfunction}

SIR: Gilleard et al (Journal, January 1987, 150, 114-117) miss the point of the paper by McDonald (1969), whose findings they claim to have disproved. Since the latter's hypothesis was essentially a predictive one which was vindicated by follow-up and confirmed by others (Naguib \& Levy, 1982) it is difficult to see how a purely cross-sectional study with no follow-up can be strictly relevant to the issue. Furthermore, Gilleard et al claim that McDonald did not exclude cases suggestive of a vascular aetiology, whereas the 1969 paper states that such exclusion did occur: "If there was a history of strokes or epileptic seizures or if there were focal neurological signs the patients were excluded as being suspect arteriosclerotic dementias". 
It is true that age and age of onset may no longer be regarded as reliable predictive factors in view of the somewhat contradictory results reported by different authors (Huff et al, 1987), but the sinister prognostic significance of visuo-spatial dysfunction must be considered as one of the most robust findings in the clinical literature on Alzheimer's disease. Its relationship to dysphasia and other focal features on the one hand and to overall severity on the other is a complex one which my group is trying to unravel in the course of a prospective study.

Institute of Psychiatry

De Crespigny Park

London SE5 8 AF

\section{Roforences}

Huff, F. J., Growdon, J. H., Corkin, C. \& Rosen, R. J. (1987) Age of onset and rate of progression of Alzheimer's disease. Journal of the American Geriatrics Association, 35, 27-30.

MCDonald, C. (1969) Clinical heterogeneity in senile dementia. British Journal of Psychiatry, 115, 267-271.

NAguti, M. \& LeVY, R. (1982) Prediction of outcome in senile dementia - a computed tomography study. British Journal of Psychiatry, 140, 263-267.

\section{Gluten Sensitivity in Schizophrenia}

SIR: Singh \& Kay (Journal, January 1987, 150, 130-131) make telling points in their criticism of our study of gluten sensitivity in schizophrenia, most of which we have already made and accept. We hardly perceived ours as the critical experiment; such experiments are difficult to perform in any science and very difficult in clinical psychiatry. They are usually misreported simplifications of the history of science. Indeed, we experienced, as others will, considerable problems in getting psychotic people to co-operate convincingly in accepting dietary controls, and so the attempt, which is what we report, was of short duration and in a special hospital. We certainly don't wish to deter others from performing more adequate work, but in our limited study the major changes occurred in the patients before they had a gluten-free period. We were pleased that, fortuitously perhaps, the Journal published Singh \& Kay's letter after one by Wing suggesting "very impaired patients" were "not impervious to social stimulation", as seemed obvious in our study.

In addition, though, we are blamed for not considering the heterogeneity of the syndrome, while in fact we discussed it and concluded that gluten-free diets may be of value to some schizophrenics. We could go on at length over details of interpretations, but perhaps it would be wisest to concede that Singh and Kay have done an immense amount of work in this field, which we took seriously enough to examine and to try to confirm. Hence we are sorry if our inability to support them in our short-term and necessarily imperfect study can be read as wishing to dismiss their efforts and their approach completely. Far from it - we want, with them, to see what other studies can demonstrate, but we needed to report what we found.

We note, though, that Singh \& Kay have written several similar letters criticising other peoples' failures to confirm their hypothesis (Singh, 1979; Singh \& Kay, 1983).

Royal Hallamshire Hospital

F. A. JENNER

D. N. Vlissides

Glossop Road, Sheffield S10 2JF

\section{References}

SINGH, M. M. (1979) Celiac-type diets in schizophrenia. American Journal of Psychiatry, 136, 733.

SinGH, M. M. \& KAY, R. S. (1983) Study of gluten efiects in schizophrenia. Archives of General Psychiatry, 40, 345.

\section{Sub-cortical Dementia}

SIR: In his review of sub-cortical dementia (Journal, December 1986, 149, 682-697) Cummings makes the statement: "Sub-cortical dementias are characterised by psychomotor retardation, whereas the cortical dementias" (among which he includes Alzheimer's disease) "manifest a normal psychomotor speed through most of the clinical course", and supports this with reference to Cummings \& Benson (1986). Although it is true that this view has become something of an orthodoxy in neurological texts, it flies in the face of much evidence from other sources. For instance, it is clear that on the Digit Copying Test (DCT) component of the Kendrick Battery (Kendrick et al, 1979) groups of patients with dementia predominantly of the Alzheimer type were significantly slower than non-demented subjects. Evidence of slowing also comes from other sources using quite different techniques. Thus slowing is also found in Alzheimer patients when they are asked to identify pictures presented tachistoscopically (Neville \& Folstein, 1979) or when they carry out tasks using a peg-board (Miller, 1977). This issue is discussed by Woods (1982), who suggests that a critical point may be the degree of cognitive load in terms of choices available. Another important variable which may be seen as a form of cognitive load is the delay involved before the subject is expected to respond. In a study using a computerised visual matching to sample task with variable delay 